\title{
Who comes back with what: A retrospective database study on reasons for emergency re-admission to hospital in children and young people in England
}

Linda PMM Wijlaars ${ }^{1,2}$, research associate in statistics

Pia Hardelid ${ }^{1,3}$, senior research associate

Jenny Woodman ${ }^{1,2}$, research associate

Janice Allister ${ }^{4}$, general practitioner

Ronny Cheung ${ }^{5}$, consultant general paediatrician

Ruth Gilbert ${ }^{1,2}$, professor of clinical epidemiology

1. Children's Policy Research Unit, UCL Institute of Child Health, London WC1N 1EH,

2. Farr Institute of Health Informatics Research London, London NW1 2DA,

3. Department of Primary Care and Population Health, University College London, UCL Royal Free Campus, London NW3 2PF,

4. Clinical Innovation and Research, Royal College of General Practitioners, London NW1 2FB,

5. Department of General Paediatrics, Evelina Children's Hospital, Guy's and St Thomas' NHS Foundation Trust, London.

Correspondence to: L Wijlaars - linda.wijlaars@ucl.ac.uk

Population, Policy and Practice, UCL Institute of Child Health,

30 Guildford Street, WC1N 1EH, London

Abstract word count: 249

Article word count: 2499

Figures / Tables: 3 / 1

eTables: 3 


\section{Abstract}

Objective - To determine the proportion of children and young people (CYP) in England who are readmitted for the same condition.

Design - Retrospective cohort study

Setting - National administrative hospital data (Hospital Episode Statistics).

Participants - CYP (0-24 year olds) discharged after an emergency admission to the NHS in England in 2009/10.

Main outcome measures - Coded primary diagnosis classified in six broad groups indicating reason for admission (infection, chronic condition, injury, perinatal- or pregnancyrelated, sign or symptom, or other). We grouped readmissions as $\leq 30$ days, or between 31 days and 2 years after the index discharge. We used multivariable logistic regression to determine factors at the index admission that were predictive of readmission within 30 days.

Results - 9\% of CYP were readmitted within 30-days. Half of the 30 day readmissions and $40 \%$ of the recurrent admissions between 30 days and 2 years had the same primary diagnosis group as the original admission. These proportions were consistent across age, sex and diagnostic groups, except for infants and young women with pregnancy-related problems (15-24 years) who were more likely to be readmitted for the same primary diagnostic group. CYP with underlying chronic conditions were readmitted within 30 days twice as often (OR: $1.93,95 \% \mathrm{Cl}: 1.89$ - 1.99) compared to CYP without chronic conditions.

Conclusions - Financial penalties for readmission are expected to incentivise more effective care of the original problem, thereby avoiding readmission. Our findings, that half of children come back with different problems, do not support this presumption. 


\section{Background}

A large proportion (32\%) of children and young people (CYP) who have an emergency hospital admission will have at least one further emergency admission during the next two years[1]. One in four of these patients are readmitted within 30 days of discharge.

Reimbursements for emergency readmissions within 30 days of discharge are restricted in the English NHS. The rule applies to all patients older than four years of age and was introduced in $2011 / 12$ to "encourage providers and commissioners to manage emergency admissions better through well-planned discharges, participation in preventative initiatives, and greater involvement of experienced clinicians earlier in the decision-making process"[2]. Evidence from the US shows that adult patients come back with different diagnoses, suggesting that not all readmissions might be preventable[3-5]. A UK study of adults found similar results and deemed only $30 \%$ of readmissions to be potentially preventable[6].

Previous studies focussed on adult populations[7], hospital factors[5,8], or specific conditions[9-11] and therefore have limited applicability to hospital care for CYP.

We aimed to evaluate the hypothesis underlying the 30-day readmission rule that readmissions are often for the original problem, focussing on CYP. We assessed the proportion of CYP readmitted for the same problem within 30 days of discharge from a previous emergency admission.

\section{Methods}

\section{Data source}

We performed a retrospective cohort study using hospital administrative data for all inpatient admissions to NHS hospitals in England (Hospital Episode Statistics (HES))[12]. 


\section{Population}

We defined a cohort of CYP who were discharged from an emergency hospital admission between 1 April 2009 and 31 March 2010, the year before the readmission rule was introduced, when they were 0-24 year old, and used the HES-ID unique patient identifier to track subsequent emergency readmissions over the next two years[13]. For detail on how we defined admissions see appendix B and previous reports[1,14].

We extracted patient characteristics including age group (<1 year, 1-4 year, 5-15 year, and 16-24 year), ethnicity and area-level deprivation (measured by quintile of the index of multiple deprivation, IMD 2004[15,16]), at index admission, or if missing, from any admission between 2009 to 2011. We classified all patients with a valid Code of GP practice as registered with a GP. If variables differed between admissions, we used the mode.

We excluded CYP who had missing information on sex (1,410, 0.2\%), IMD (13,027, 1.5\%), or ethnicity $(71,446,8.3 \%)$ as these children were less likely to be linked longitudinally via their HES-ID. CYP with missing data could receive a different HES-ID on readmission, leading to missed matches. In the absence of patient identifiers, it is not possible to detect these patients[17]. As missing data often occurred in multiple variables, we excluded 72,542 CYP in total $(8.4 \%)$

\section{Primary diagnosis at admission}

We used the primary diagnosis of the first (and in most cases the only) finished consultant episode recorded during the admission to indicate the clinical reason for the index admission. The primary diagnosis is determined and entered by professional NHS coders after discharge and is defined as the main condition treated or investigated during the relevant episode of healthcare[19]. For statistical analysis, we defined six broad groups of ICD-10 diagnostic codes recorded in the primary diagnosis: infection[20], chronic condition[14], injury[21], pregnancy or perinatal-related[1], sign or symptom (ICD-10 chapter 18), or other for all residual diagnoses. To determine the impact of the grouping of codes, we 
also grouped the primary diagnosis by 23 ICD-10 chapters (codes for groupings listed in Appendix B).

\section{Analysis}

We stratified analyses by age group. We determined the proportion of patients who had an emergency readmission within 30 days or between 31 days and 2 years of the date of discharge of the index admission discharge, for whom the primary diagnosis was in the same group of ICD10 codes (i.e. same of 6 groups, or ICD10 chapters) at both the index and recurrent admission. We only used the first recurrent admission, resulting in mutually exclusive 30-day readmission/<2 year recurrent admission groups. To limit the risk of disclosure, we only included the ten most commonly recorded ICD10 chapters for each age group, grouping the remainder of primary diagnosis groups in an 'other' category.

We used logistic regression to identify patient characteristics associated with 30-day readmissions, using information available on index admission (sex, age, indication, ethnicity, IMD quintile, underlying chronic conditions, and GP registration). We determined underlying chronic conditions by assessing inclusion of codes for chronic conditions[14] in any diagnosis code entered during an admission in the previous year (2008/09). We did not include this variable for infants. We compared CYP who had a 30-day readmission with CYP who had no recurrent admission or a recurrent admission later than 30 days after index admission discharge. We used robust standard errors for parameter estimates to correct for clustering by hospital.

We conducted a sensitivity analysis to determine whether the proportion of readmissions with diagnostic codes from a different group diminished when all 20 diagnostic fields (mean number recorded is 2.9 diagnosis codes, sd: 2.2) were considered at the index admission.

All analyses were performed using Stata SE version 13.0. The interactive bipartite graphs were created using D3 block \#9796212 [22]. The Treemap was created using Google Charts. 


\section{Results}

We included 866,221 children with at least one emergency admission. Emergency readmissions occurred within 30 days of discharge for 76,234 CYP $(8.8 \%$ of index admissions) and between 30 days and 2 years for 193,988 CYP (22.4\% of index admissions).

The primary diagnosis at index emergency admission varied by age (Figure 1). Infections accounted for half of the primary diagnoses in infants and children aged 1-4 years. The prevalence of injury admissions increased with age.

$50 \%$ (infants) to $60 \%$ (16-24 year olds) of CYP who were readmitted within 30 days after index discharge had a primary diagnosis from the same broad coding group on both index and readmission (Table 1). For later recurrent admissions 35 to $40 \%$ had a similar primary diagnosis. Similar results were found for the code groupings by ICD-10 chapter.

Proportions of readmissions for the same primary diagnosis group as the index admission were similar to the overall findings (Figure 2, Appendix C). Young children $(<1$ year and 1-4 year) who had infection were more likely to come back with the same problem than was the case for other conditions ( $72 \%$ and $74 \%$, respectively). Young women who had a pregnancyrelated primary diagnosis at index admission came back with the same problem in $88 \%$ of 30-day readmissions.

Readmission within 30 days was more likely in CYP with underlying chronic conditions (OR: 1.93, 95\% Cl: 1.89-1.99, Figure 3 and eTable 1 in Appendix A), girls (OR: 1.04, 95\% Cl: 1.02-1.05), and more deprived CYP (most deprived compared to least deprived, OR: 1.06, 95\% Cl: 1.03-1.09, eTable 2 in Appendix A). Readmission was less likely in CYP who were not registered with a GP (OR: $0.88,95 \% \mathrm{Cl}: 0.84-0.93)$, or had unstated ethnicity (OR: 0.60 , 95\% CI: 0.55-0.63). Similarly, CYP with missing data on IMD or ethnicity were less likely to be readmitted (data not shown). 
For infants, chronic conditions were the strongest predictor for 30-day readmissions among the six primary diagnosis groups (OR: $3.31,95 \% \mathrm{Cl}: 2.96-3.71$ ), while overall perinatal/pregnancy related primary diagnoses were the strongest predictor (OR: 3.02, 95\% $\mathrm{Cl}$ : 2.92-3.11). Admissions with injury-related primary diagnoses were least likely to result in a 30-day readmission across all age groups. Overall, effect estimates were consistent across age groups, apart from sex which was reversed in infants and children age 1-4 years where girls were less likely to have a readmission (OR: $0.88,95 \% \mathrm{Cl}: 0.85-0.90$ and OR: 0.96, 95\% Cl: 0.93-1.00, respectively).

\section{Sensitivity analysis}

When all diagnostic fields were included for the index admission, the rates of recurrent admissions with the same indication as index admission increased to $71-77 \%$ for $<30$-day readmissions and $49-56 \%$ for later recurrent admissions for the broad groupings. For groupings by ICD-10 chapter, the proportion of readmissions with similar primary diagnoses increased to $59-70 \%$ for $<30$-day readmissions, and to $28-42 \%$ for later recurrent admissions (ranges reflect different age groups, eTable 3 in Appendix A).

\section{Discussion}

Overall, 8.8\% of CYP who had an emergency hospital admission between 1 April 2009 and 31 March 2010 were readmitted within 30 days. CYP with an emergency readmission had the same primary diagnosis at readmission and index admission in $50-60 \%$ of 30 -day readmissions (infants and 16-24 year olds, respectively). In recurrent admissions that happen between 30 days and two years after index admission discharge, $35-40 \%$ of CYP had the same primary diagnosis.

We found that children aged 1-4 years were less likely than older children to have readmissions for the same indication as index admission, supporting the exemption from the 30-day readmission rule for children up to age 4 years. However, the difference with older 
age groups was small. This suggests that extending the age exemption to older age groups or abolishing the penalty tariff would not have a significant effect on the number of readmissions for similar diagnoses.

Our findings are consistent with studies in adults: in a US study using Medicare data on patients aged 65 years and older, only $40-50 \%$ of patients had a similar indication on readmission compared to their index admission[23]. In addition, two US studies found that rates of readmission varied by condition, with rates ranging from $21 \%$ to $86 \%[7,24]$. The latter estimate is closer to our estimate of $66-75 \%$ when considering all diagnoses recorded at index admission.

A UK study on readmission found that $30 \%$ of readmissions were broadly related to the previous admission[6]. Their estimate is likely lower than our finding of $50 \%$ as they also included elective index admissions and used a different classification method.

Several studies have found increases in readmission rates associated with children with chronic conditions[25,26]: a US study found that patient had chronic conditions in $78 \%$ of readmissions. [27].

\section{Strengths and limitations}

We found that CYP who had missing data on ethnicity and/or IMD were less likely to be readmitted compared to CYP without missing data on these variables. This may be associated with incomplete or erroneous identifiers, thereby reducing the chance of linkage to a subsequent admission[16,28].

Our results are likely to overestimate the proportion of CYP who are readmitted with the same problem because of our relatively broad groupings and hospital coding practices. For instance, patients who have been admitted with an infection as a primary diagnosis on original and readmission are classified as having the same problem, while in fact they could have had two unrelated infections (e.g. an urinary tract infection and a lower respiratory tract 
infection). Although we expect this limitation to affect the grouping by ICD10 chapter to a lesser extent, it could still apply (e.g. admissions for acute tonsillitis (J03) and asthma (J45) which would both be classified as diseases of the respiratory system).

In addition, we performed sensitivity analyses where we included all diagnoses entered during index admission. However, our results were very similar, indicating that readmissions are often for reasons not recorded on index admission, either as primary, or subsidiary diagnosis.

Coding from a previous admission could have influenced primary diagnosis code entry at a subsequent readmission as hospital coders often have access to information from previous hospital visits or the full medical record upon data entry (personal communication with University College London Hospital clinical coding department). As financial reimbursements favour certain high tariff diagnoses, coders could favour similar primary diagnosis codes that attract high tariffs, for instance in patients with chronic conditions. Similarly, if coders are aware of the rules for readmission penalties, this could influence coded diagnoses. However, there are strict rules in order to ensure consistent and fair coding.

In addition, our sensitivity analysis, where we included all diagnoses codes recorded on index admission rather than just the primary diagnoses, showed similar results to the main results, albeit with slightly higher proportions of similar diagnoses. This strengthens our overall finding and suggests that hospitals do not 'game' readmission reimbursements by entering similar primary diagnoses for both the index and subsequent readmissions.

Due to the nature of HES data, we were unable to determine whether children were admitted to paediatric wards or observation units.

Finally, we have limited our analyses to emergency admissions and first readmissions, excluding CYP who had elective index admissions or multiple readmissions, as this was beyond the scope of this paper. 


\section{Policy context}

Policy makers need to balance potential benefits and harms of using tariffs to disincentivise hospital readmissions. The NHS England engagement documents for the 2015/16 National Tariff announced that they will review the 30-day readmission penalty (as well as the marginal rate rule, which sets a baseline level of emergency admissions above which providers are paid $30 \%$ of the national price for admissions) for subsequent years[31]. The $\mathrm{NHS}$ in England is one of many healthcare systems to use tariffs to disincentivise hospital readmissions. Our results suggest that reduction in payments for readmissions may penalise provision of care which is not directly amenable to intervention during the index admission. However, further research on more recent data after the introduction of this rule is needed to confirm this. In addition, these penalties may impact most on children with chronic conditions. Our findings likely reflect the variety of health problems occurring in children, although further evaluation is needed in non-NHS settings.

\section{Implications for policy and practice}

Our findings, that around half of readmissions are for a different condition, suggest that indiscriminate penalties for all readmissions are poorly supported by evidence. The variation in proportion of readmission that occur for the same reason as on index admission across different conditions found in various studies further suggest the evidence available does not support unselective policy measures. For health care providers, the findings suggest that services need to address holistic care needs in addition to the problem at the index admission, to reduce the frequency and severity of subsequent episodes of ill health. However, whether more effective and holistic care should be measured in terms of reduced (re)admissions, or should be delivered in the community or hospital is far from certain. Undoubtedly, reduced readmissions reduce health care costs but are not clearly linked to improved quality of care in children[32]. There is also a lack of evidence for effective interventions to reduce readmissions[33]. A recent systematic review on interventions to 
reduce 30-day readmissions identified 43 studies testing various pre- and post-discharge interventions as well as interventions that bridged the transition from hospital to primary care, none of which were consistently associated with a reduced risk for 30-day readmissions[34].This review excluded studies involving children. A few interventions aimed at CYP[35], such as structured discharge procedures for asthmatic children[36], clinical pathways for infants with bronchiolitis[37], or a transition care programme for young adults with type 1 diabetes[38], have achieved reductions in readmission rates. However, these interventions included small patient groups and have limited reproducibility[39].

Given the uncertain evidence, policy makers should prioritise evaluation of the 30-day readmission rule and reconsider disincentivising hospital readmissions until the benefits of the policy can be established.

\section{Footnotes}

Licence statement: The Corresponding Author has the right to grant on behalf of all authors and does grant on behalf of all authors, an exclusive licence (or non-exclusive for government employees) on a worldwide basis to the BMJ and co-owners or contracting owning societies (where published by the BMJ on their behalf), and its Licensees to permit this article (if accepted) to be published in Archives of Disease in Childhood and any other BMJ products and to exploit all subsidiary rights, as set out in our licence.

Contributor Statement: RG and LW conceived the paper and the statistical analysis plan. LW cleaned and analysed the data, and drafted and revised the paper. RG acquired the data and is guarantor. PH contributed to the design of the study, interpretation of results, and revised the paper. JW, JA and $\mathrm{RC}$ helped interpret the data, and revised the paper. All authors commented on the analyses and report, and read and approved the final manuscript.

Competing interests: All authors have completed the ICMJE uniform disclosure form at www.icmje.org/coi disclosure.pdf and declare: LW and JW were supported by funding from the Department of Health Policy Research Programme through funding to the Policy Research Unit in the Health of Children, Young People and Families. This is an independent report commissioned and funded by the Department of Health. The views expressed are not necessarily those of the Department.

We also acknowledge the support from the Farr Institute of Health Informatics Research (MRC Grant Nos: London MR/ K006584/1).

No financial relationships with any organisations that might have an interest in the submitted work in the previous three years; no other relationships or activities that could appear to have influenced the submitted work. 
Ethical approval: Not required for this study.

Data sharing statement: Additional data can be accessed in the appendices. Source data can be accessed by researchers applying to the Health and Social Care Information Centre for England. Copyright (C) 2015, Re-used with the permission of the Health and Social Care Information Centre. All rights reserved.

Transparency declaration: The lead author affirms that this manuscript is an honest, accurate, and transparent account of the study being reported; that no important aspects of the study have been omitted; and that any discrepancies from the study as planned (and, if relevant, registered) have been explained. 


\section{What is already known on this topic:}

- In children and young people, recurrent admissions make up $41 \%$ of all emergency admissions and account for $66 \%$ of bed days over a 2 year period.

- The UK government has implemented financial incentives to decrease the number of 30-day readmissions as these are deemed to be avoidable failures of hospital care

- Research in adults found that 30 to $50 \%$ of 30 -day readmissions (depending on indication on index admission) were for a different primary diagnosis from the original admission

\section{What this study adds:}

- Half the children and young people who were readmitted within 30 days came back with a different primary diagnosis

- Emergency re-admissions within 30 days were twice as likely in children with underlying chronic conditions: they occurred in $16 \%$ of patients with, compared to $8 \%$ of patients without chronic conditions.

- Our findings do not support the presumption that financial penalties for readmission incentivise more effective care of the original problem. 


\section{References}

1 Wijlaars L, Hardelid P, Woodman J, et al. Contribution of recurrent admissions in children and young people to emergency hospital admissions: retrospective cohort analysis of hospital episode statistics. Arch Dis Child in press.

2 NHS England, Monitor. The 2014/15 National Tariff Payment System. 2014. http://bit.ly/1hSyccL

3 Van Walraven C, Jennings A, Forster AJ. A meta-analysis of hospital 30-day avoidable readmission rates. J Eval Clin Pract 2012;18:1211-8. doi:10.1111/j.13652753.2011.01773.x

4 Donzé J, Lipsitz S, Bates DW, et al. Causes and patterns of readmissions in patients with common comorbidities: retrospective cohort study. BMJ 2013;347:f7171.

5 Callery P, Kyle RG, Campbell M, et al. Readmission in children's emergency care: an analysis of hospital episode statistics. Arch Dis Child 2010;95:341-6. doi:10.1136/adc.2009.163261

6 Blunt I, Bardsley M, Grove A, et al. Classifying emergency 30-day readmissions in England using routine hospital data 2004-2010: what is the scope for reduction? Emerg Med J 2014;::emermed - 2013-202531. doi:10.1136/emermed-2013-202531

7 Jencks SF, Williams MV, Coleman EA. Rehospitalizations among Patients in the Medicare Fee-for-Service Program. N Engl J Med 2009;360:1418-28. doi:10.1056/NEJMsa0803563

8 Stukel TA, Fisher ES, Alter DA, et al. Association of hospital spending intensity with mortality and readmission rates in Ontario hospitals. JAMA 2012;307:1037-45. doi:10.1001/jama.2012.265

9 Springel T, Laskin B, Furth S. Readmission within 30 days of hospital discharge among children receiving chronic dialysis. Clin J Am Soc Nephrol CJASN 2014;9:536-42. doi:10.2215/CJN.05410513

10 Reznik M, Hailpern SM, Ozuah PO. Predictors of early hospital readmission for asthma among inner-city children. $J$ Asthma Off J Assoc Care Asthma 2006;43:37-40. doi:10.1080/02770900500446997

11 Neuman MI, Hall M, Gay JC, et al. Readmissions among children previously hospitalized with pneumonia. Pediatrics 2014;134:100-9. doi:10.1542/peds.2014-0331

12 Health and Social Care Information Centre 1 Trevelyan Square. Hospital Episode Statistics. 2012.http://www.hscic.gov.uk/hes (accessed 28 Aug2014).

13 Health \& Social Care Information Centre. Methodology for creation of the HES Patient ID (HESID). 2014. http://www.hscic.gov.uk/media/1370/HES-Hospital-EpisodeStatistics-Replacement-of-the-HES-patient-ID/pdf/HESID_Methodology.pdf

14 Hardelid P, Dattani N, Davey J, et al. Overview of child deaths in the four UK countries. HQIP bit.ly/hardelidreport

15 Department for Communities and Local Government. Index of Multiple Deprivation 2004. 2010.http://data.gov.uk/dataset/imd_2004 (accessed 1 Dec2014). 
16 Mathur R, Bhaskaran K, Chaturvedi N, et al. Completeness and usability of ethnicity data in UK-based primary care and hospital databases. J Public Health 2013;;fdt116. doi:10.1093/pubmed/fdt116

17 Hagger-Johnson G. Identifying possbile false matches in anonymised hospital administrative data without patient identifiers. Health Serv Res In press.

18 NHS Information Centre. How good is HES ethnic coding where do the problems lie? Revised for the 2009-2010 HES Data Year. 2011.

19 Attribute: PRIMARY DIAGNOSIS.

http://www.datadictionary.nhs.uk/data_dictionary/attributes/p/prev/primary_diagnosis_de.a sp?shownav=1 (accessed 3 Dec2014).

20 Baker MG, Barnard LT, Kvalsvig A, et al. Increasing incidence of serious infectious diseases and inequalities in New Zealand: a national epidemiological study. The Lancet 2012;379:1112-9. doi:10.1016/S0140-6736(11)61780-7

21 González-Izquierdo A, Cortina-Borja M, Woodman J, et al. Maltreatment or violencerelated injury in children and adolescents admitted to the NHS: comparison of trends in England and Scotland between 2005 and 2011. BMJ Open 2014.

22 NPashaP. block \#9796212. 2014. http://bl.ocks.org/NPashaP/9796212

23 Dharmarajan K, Hsieh AF, Lin Z, et al. Hospital readmission performance and patterns of readmission: retrospective cohort study of Medicare admissions. BMJ 2013;347:f6571-f6571. doi:10.1136/bmj.f6571

24 Berry JG, Toomey SL, Zaslavsky AM, et al. Pediatric readmission prevalence and variability across hospitals. JAMA 2013;309:372-80. doi:10.1001/jama.2012.188351

25 Berry JG, Hall DE, Kuo DZ, et al. Hospital utilization and characteristics of patients experiencing recurrent readmissions within children's hospitals. JAMA 2011;305:682-90. doi:10.1001/jama.2011.122

26 Feudtner C, Levin JE, Srivastava R, et al. How Well Can Hospital Readmission Be Predicted in a Cohort of Hospitalized Children? A Retrospective, Multicenter Study. Pediatrics 2009;123:286-93. doi:10.1542/peds.2007-3395

27 Gay JC, Hain PD, Grantham JA, et al. Epidemiology of 15-Day Readmissions to a Children's Hospital. Pediatrics 2011;127:e1505-12. doi:10.1542/peds.2010-1737

28 Aspinall PJ, Jacobson B. Why poor quality of ethnicity data should not preclude its use for identifying disparities in health and healthcare. Qual Saf Health Care 2007;16:176-80. doi:10.1136/qshc.2006.019059

29 Hain PD, Gay JC, Berutti TW, et al. Preventability of early readmissions at a children's hospital. Pediatrics 2013;131:e171-81. doi:10.1542/peds.2012-0820

30 Gay JC, Agrawal R, Auger KA, et al. Rates and impact of potentially preventable readmissions at children's hospitals. J Pediatr 2015;166:613-9.e5.

doi:10.1016/j.jpeds.2014.10.052 
31 Monitor, NHS England. 2015/16 National Tariff Payment System: tariff engagement documents overview. 2014. https://www.gov.uk/government/consultations/nhs-nationaltariff-payment-system-201516-engagement-documents (accessed 3 Dec2014).

32 Bardach NS, Vittinghoff E, Asteria-Peñaloza R, et al. Measuring Hospital Quality Using Pediatric Readmission and Revisit Rates. Pediatrics 2013;132:429-36. doi:10.1542/peds.2012-3527

33 Nakamura MM, Toomey SL, Zaslavsky AM, et al. Measuring pediatric hospital readmission rates to drive quality improvement. Acad Pediatr 2014;14:S39-46. doi:10.1016/j.acap.2014.06.012

34 Hansen LO, Young RS, Hinami K, et al. Interventions to Reduce 30-Day Rehospitalization: A Systematic Review. Ann Intern Med 2011;155:520-8. doi:10.7326/0003-4819-155-8-201110180-00008

35 Auger KA, Kenyon CC, Feudtner C, et al. Pediatric hospital discharge interventions to reduce subsequent utilization: a systematic review. J Hosp Med 2014;9:251-60. doi:10.1002/jhm.2134

36 Wesseldine LJ, McCarthy P, Silverman M. Structured discharge procedure for children admitted to hospital with acute asthma: a randomised controlled trial of nursing practice. Arch Dis Child 1999;80:110-4. doi:10.1136/adc.80.2.110

37 Cheney J, Barber S, Altamirano L, et al. A Clinical Pathway for Bronchiolitis is Effective in Reducing Readmission Rates. J Pediatr 2005;147:622-6. doi:10.1016/j.jpeds.2005.06.040

38 Holmes-Walker DJ, Llewellyn AC, Farrell K. A transition care programme which improves diabetes control and reduces hospital admission rates in young adults with Type 1 diabetes aged 15-25 years. Diabet Med 2007;24:764-9. doi:10.1111/j.14645491.2007.02152.x

39 Agarwal R, Mughal Z, Anderton J, et al. Nurse-led asthma education and childhood asthma readmission rates. Arch Dis Child 1999;81:278-278. doi:10.1136/adc.81.3.278f 


\section{Tables}

\begin{tabular}{|l|c|c|}
\hline \multicolumn{3}{|c|}{$\begin{array}{l}\text { Table 1: Proportion of recurrent admissions that have } \\
\text { the same primary diagnosis as the index admission }\end{array}$} \\
\hline 6 Groups & $<30$ day & $\begin{array}{c}\geq 30 \text { day, }<2 \\
\text { years }\end{array}$ \\
\hline Infants (0 years) & $10,724(57.5)$ & $16,255(36.8)$ \\
\hline 1-4 year & $11,610(60.9)$ & $23,311(43.7)$ \\
\hline 5-15 year & $9,789(60.5)$ & $16,510(43.0)$ \\
\hline 16-24 year & $26,446(61.9)$ & $44,244(41.1)$ \\
\hline ICD-10 chapter & & \\
\hline Infants (0 years) & $9,337(50.1)$ & $9,313(21.1)$ \\
\hline 1-4 year & $9,677(52.8)$ & $17,175(32.2)$ \\
\hline 5-15 year & $9,382(58.0)$ & $15,194(39.6)$ \\
\hline 16-24 year & $25,670(60.1)$ & $41,081(38.2)$ \\
\hline
\end{tabular}

\section{Figures}

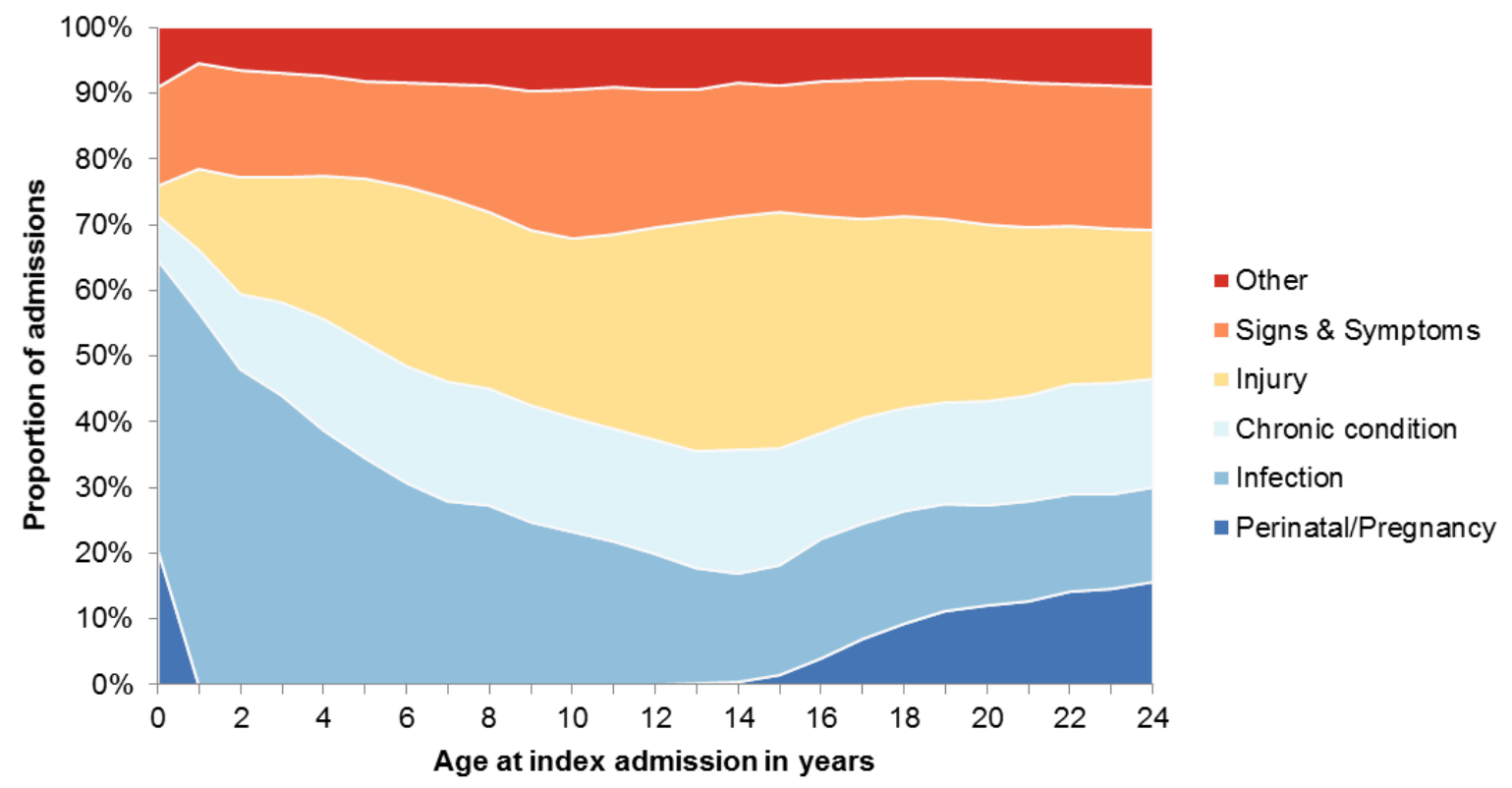

Figure 1: primary diagnosis at first emergency admission in 2009 
Infants

Click here for: Grouping by ICD-10 chapter

Click here for: 1 - 4 years, $\underline{5-15 \text { years, }}$, or $16-24$ years

\section{0 day readmissions}

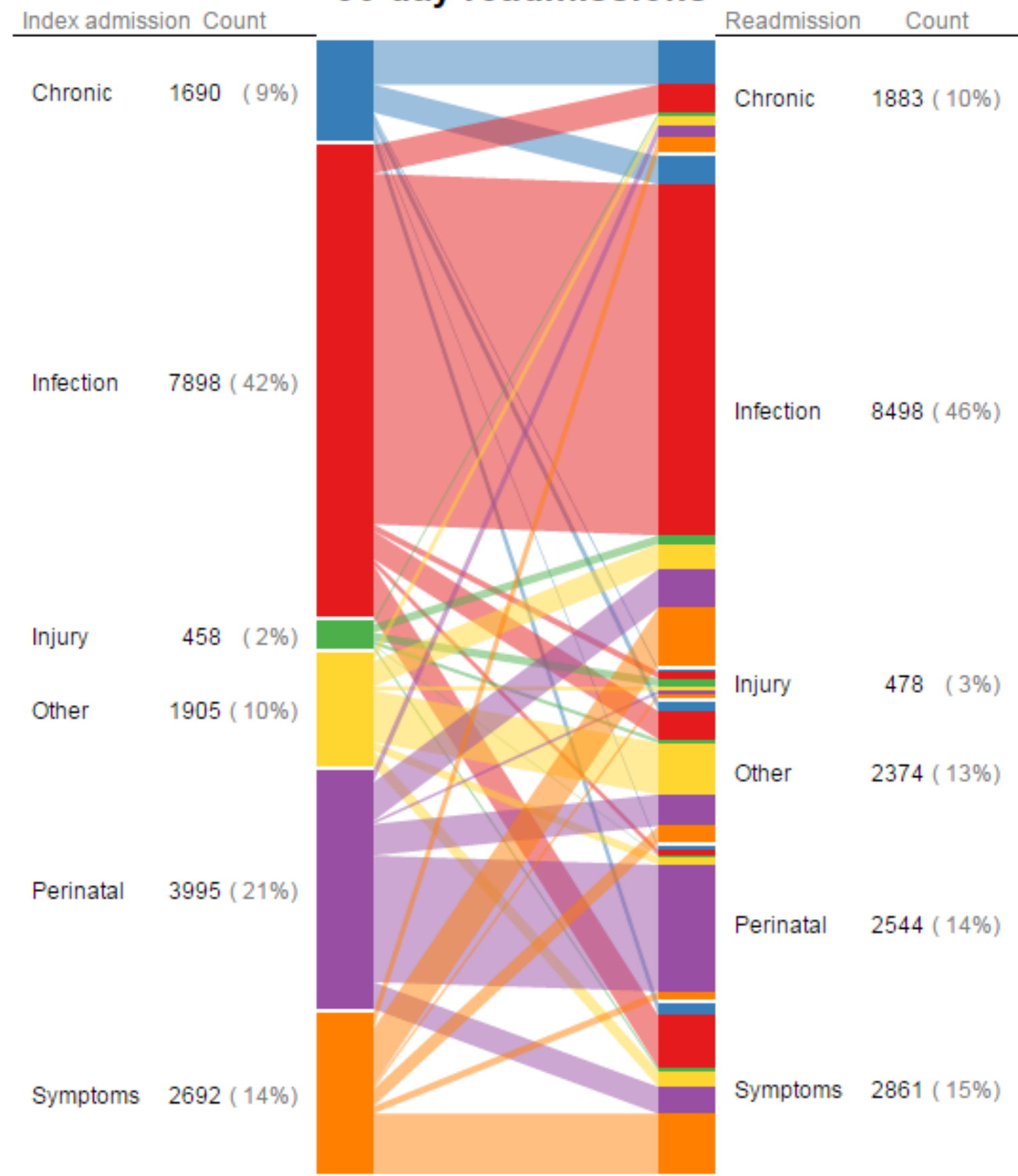

Figure 2: Primary diagnosis at index and readmission for infants (6 broad groups).

Small numbers ( $<10$ patients) were rounded up to ten to preserve patient anonymity. 


\section{TreeMap of predictors of readmission}

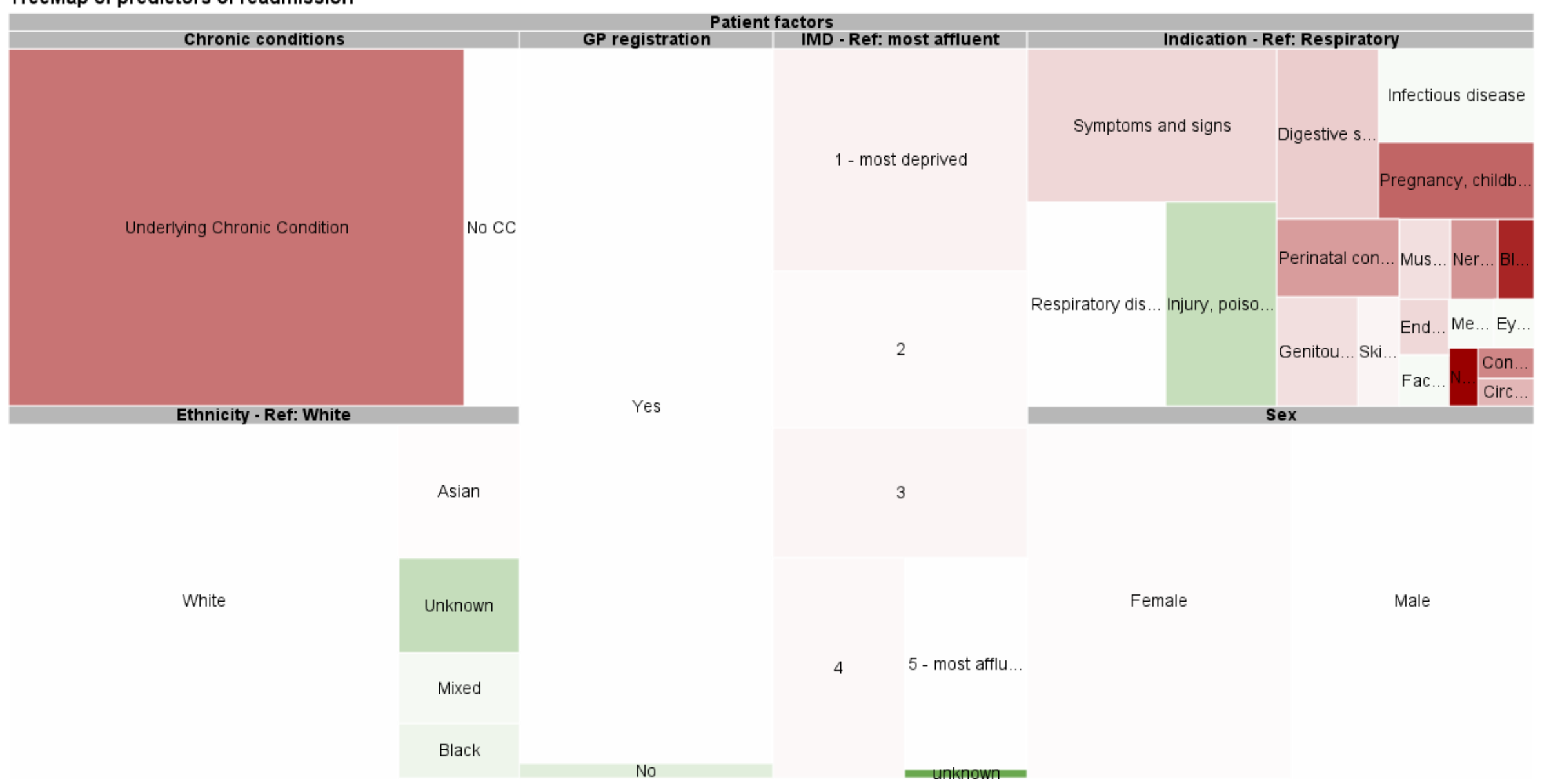

Figure 3: Treemap of predictors of 30-day readmissions - size reflects prevalence of different patient factor, colour represents estimated effect size of risk factors that increase (red) or decrease (green) the likelihood of readmission, calculated using multivariable logistic regression. Details on prevalence (eTable 1) and effect size (eTable 2) available in appendices. (Interactive version) 
Appendix A - Additional tables

\begin{tabular}{|c|c|c|c|c|c|}
\hline $\begin{array}{l}\text { Age group } \\
(\% \text { who are } \\
\text { readmitted } \\
\text { within } 30 \text { days, } \\
\text { total) }\end{array}$ & $\begin{array}{c}\text { Infants } \\
(12.2 \%, \\
152,558)\end{array}$ & $\begin{array}{c}1-4 \text { years } \\
(7.7 \% \text {, } \\
197,227)\end{array}$ & $\begin{array}{c}5-15 \text { years } \\
(7.4 \%, \\
213,800)\end{array}$ & $\begin{array}{c}\text { 16-24 years } \\
(8.8 \% \text {, } \\
302,636)\end{array}$ & $\begin{array}{c}\text { Overall } \\
(8.8 \%, \\
866,221)\end{array}$ \\
\hline \multicolumn{6}{|l|}{ GP registration } \\
\hline Yes & $18,001(12.2)$ & $14,968(7.7)$ & $15,727(7.5)$ & $25,838(9.0)$ & $74,534(8.9)$ \\
\hline No & $533(11.0)$ & $146(5.4)$ & $119(4.0)$ & $774(4.9)$ & $1,572(6.0)$ \\
\hline \multicolumn{6}{|l|}{ Sex } \\
\hline Boys & $10,948(12.8)$ & $8,648(7.8)$ & $8,045(6.8)$ & $9,085(7.1)$ & $36,726(8.3)$ \\
\hline Girls & $7,586(11.4)$ & $6,466(7.5)$ & 7,801 (8.2) & $17,527(10.0)$ & $39,380(9.3)$ \\
\hline \multicolumn{6}{|l|}{$\begin{array}{l}\text { Primary } \\
\text { diagnosis group }\end{array}$} \\
\hline Infection & $8,151(11.6)$ & $7,472(7.6)$ & 3,729 (7.3) & 3,597 (7.2) & $22,949(8.5)$ \\
\hline $\begin{array}{c}\text { Chronic } \\
\text { condition* }\end{array}$ & $1,976(17.4)$ & $2,688(11.0)$ & $4,001(10.2)$ & $5,143(9.9)$ & $\begin{array}{l}13,808 \\
(10.9)\end{array}$ \\
\hline Injury & $398(5.9)$ & $1,293(4.1)$ & $2,655(4.2)$ & $4,652(5.9)$ & $8,998(5.0)$ \\
\hline $\begin{array}{l}\text { Perinatal / } \\
\text { pregnancy }\end{array}$ & $3,519(12.8)$ & - & $52(11.3)$ & $5,084(15.2)$ & $8,657(14.0)$ \\
\hline Symptoms & $2,612(11.5)$ & $2,606(8.3)$ & $3,943(9.6)$ & $5,872(9.3)$ & $15,033(9.5)$ \\
\hline Other & $1,878(13.7)$ & $1,053(8.6)$ & $1,466(7.8)$ & 2,264 (9.2) & $6,661(9.6)$ \\
\hline \multicolumn{6}{|l|}{$\begin{array}{l}\text { Underlying } \\
\text { chronic } \\
\text { condition* }\end{array}$} \\
\hline Yes & 6,646 (22.9) & $2,060(15.2)$ & $2,137(15.4)$ & $3,620(15.6)$ & $\begin{array}{c}14,463 \\
(15.8)\end{array}$ \\
\hline No & $12,386(9.7)$ & $13,077(7.1)$ & $13,710(6.9)$ & 22,889 (8.2) & $62,062(8.3)$ \\
\hline \multicolumn{6}{|l|}{ Ethnicity } \\
\hline White & $14,136(12.5)$ & $11,089(7.8)$ & $12,151(7.6)$ & $21,225(9.1)$ & $58,601(9.0)$ \\
\hline Black & $576(10.3)$ & $602(7.0)$ & $599(7.4)$ & $1,090(10.1)$ & $2,867(8.7)$ \\
\hline Asian & $1,914(12.7)$ & $1,701(8.5)$ & $1,474(8.5)$ & $1,791(9.8)$ & $6,880(9.8)$ \\
\hline Mixed & $1,030(11.4)$ & $886(7.5)$ & $676(7.5)$ & 1,050 (8.3) & $3,642(8.6)$ \\
\hline Missing & $874(9.4)$ & $826(6.0)$ & $936(4.9)$ & $1,448(5.3)$ & $4,084(5.9)$ \\
\hline \multicolumn{6}{|l|}{ IMD quintile } \\
\hline $\begin{array}{l}1-\text { most } \\
\text { deprived }\end{array}$ & $5,829(12.8)$ & $4,353(7.5)$ & $4,159(7.2)$ & $8,843(9.6)$ & $23,184(9.2)$ \\
\hline 2 & 4,038 (12.2) & $3,178(7.6)$ & $3,129(7.3)$ & $5,976(8.9)$ & $16,321(8.8)$ \\
\hline 3 & 3,237 (12.1) & $2,755(8.1)$ & 2,895 (7.6) & $4,703(8.9)$ & $13,590(8.9)$ \\
\hline 4 & $2,823(11.9)$ & $2,448(7.8)$ & $2,797(7.8)$ & $3,767(8.5)$ & $11,835(8.8)$ \\
\hline $\begin{array}{l}5-\text { most } \\
\text { affluent }\end{array}$ & $2,524(11.5)$ & $2,305(7.7)$ & $2,785(7.7)$ & $3,128(7.9)$ & $10,742(8.4)$ \\
\hline Missing & $83(4.8)$ & $75(3.6)$ & $81(3.1)$ & $195(3.0)$ & $434(3.3)$ \\
\hline
\end{tabular}




\begin{tabular}{|c|c|c|c|c|c|}
\hline Age group & Infants & $1-4$ years & $5-15$ years & $16-24$ years & Overall \\
\hline & OR $(95 \% \mathrm{Cl})$ & OR $(95 \% \mathrm{Cl})$ & OR $(95 \% \mathrm{Cl})$ & OR $(95 \% \mathrm{Cl})$ & OR $(95 \% \mathrm{Cl})$ \\
\hline \multicolumn{6}{|l|}{ GP registration } \\
\hline Yes & Ref & Ref & Ref & Ref & Ref \\
\hline No & $0.91(0.83-1.00)$ & $0.80(0.67-0.95)$ & $0.68(0.56-0.82)$ & $0.68(0.63-0.73)$ & $0.88(0.84-0.93)$ \\
\hline \multicolumn{6}{|l|}{ Sex } \\
\hline Boys & Ref & Ref & Ref & Ref & Reference \\
\hline Girls & $0.88(0.85-0.90)$ & $0.96(0.93-1.00)$ & $1.13(1.10-1.17)$ & $1.14(1.11-1.17)$ & $1.04(1.02-1.05)$ \\
\hline \multicolumn{6}{|l|}{ Primary diagnosis group } \\
\hline Infection & $2.06(1.86-2.29)$ & $1.82(1.71-1.93)$ & $1.80(1.71-1.90)$ & $1.17(1.12-1.23)$ & $1.67(1.62-1.71)$ \\
\hline Chronic condition & $3.31(2.96-3.71)$ & $2.86(2.67-3.06)$ & $2.26(2.14-2.39)$ & $1.64(1.58-1.71)$ & $2.08(2.02-2.14)$ \\
\hline Injury & Ref & Ref & Ref & Ref & Ref \\
\hline Perinatal / pregnancy & $2.11(2.15-2.70)$ & - & $2.28(1.70-3.06)$ & $2.44(2.33-2.56)$ & $3.02(2.92-3.11)$ \\
\hline Symptoms & $2.02(1.81-2.25)$ & $2.03(1.89-2.17)$ & $2.35(2.24-2.48)$ & $1.51(1.45-1.57)$ & $1.92(1.87-1.98)$ \\
\hline Other & $2.41(2.15-2.70)$ & $2.15(1.98-2.34)$ & $1.89(1.77-2.02)$ & $1.52(1.44-1.61)$ & $1.95(1.88-2.01)$ \\
\hline \multicolumn{6}{|c|}{ Underlying chronic condition } \\
\hline Yes & $3.48(3.34-3.62)$ & $2.11(2.00-2.22)$ & $2.08(1.98-2.19)$ & $2.01(1.92-2.11)$ & $1.93(1.89-1.99)$ \\
\hline No & Ref & Ref & Ref & Ref & Ref \\
\hline \multicolumn{6}{|l|}{ Ethnicity } \\
\hline White & Ref & Ref & Ref & Ref & Ref \\
\hline Black & $0.77(0.70-0.84)$ & $0.88(0.81-0.96)$ & $0.94(0.86-1.02)$ & $1.05(0.98-1.12)$ & $0.91(0.87-0.95)$ \\
\hline Asian & $0.98(0.93-1.03)$ & $1.09(1.03-1.15)$ & $1.09(1.03-1.16)$ & $1.04(0.99-1.09)$ & $1.03(1.00-1.05)$ \\
\hline Mixed & $0.89(0.83-0.95)$ & $0.97(0.90-1.05)$ & $1.01(0.93-1.09)$ & $0.93(0.87-0.99)$ & $0.94(0.91-0.98)$ \\
\hline \multicolumn{6}{|l|}{ IMD quintile } \\
\hline 1 - most deprived & $1.15(1.09-1.21)$ & $0.96(0.91-1.01)$ & $0.90(0.85-0.94)$ & $1.12(1.08-1.17)$ & $1.06(1.03-1.09)$ \\
\hline 2 & $1.08(1.03-1.14)$ & $0.98(0.92-1.03)$ & $0.90(0.86-0.95)$ & $1.06(1.01-1.10)$ & $1.02(1.00-1.05)$ \\
\hline 3 & $1.06(1.00-1.12)$ & $1.04(0.98-1.11)$ & $0.96(0.91-1.02)$ & $1.09(1.04-1.14)$ & $1.05(1.02-1.07)$ \\
\hline 4 & $1.04(0.98-1.10)$ & $1.02(0.96-1.08)$ & $1.00(0.95-1.06)$ & $1.06(1.01-1.11)$ & $1.04(1.01-1.07)$ \\
\hline $5-$ most affluent & Ref & Ref & Ref & Ref & Ref \\
\hline Age & $0.96(0.95-0.97)^{*}$ & $0.89(0.88-0.90)$ & $1.03(1.03-1.04)$ & $1.02(1.01-1.02)$ & $1.00(1.00-1.00)$ \\
\hline
\end{tabular}




\begin{tabular}{|c|c|c|}
\hline \multicolumn{3}{|c|}{$\begin{array}{l}\text { eTable 3: Sensitivity analysis: proportion of recurrent } \\
\text { admissions where the indication was included as a } \\
\text { primary or subsidiary diagnosis on index admission }\end{array}$} \\
\hline 6 Groups & $<30$ day & $\begin{array}{c}\geq 30 \text { day, }<2 \\
\text { years }\end{array}$ \\
\hline Infants (0 years) & $14,192(70.8)$ & $24,021(48.7)$ \\
\hline 1-4 year & $13,359(75.2)$ & $31,376(56.1)$ \\
\hline 5-15 year & 11,866 (73.9) & $21,783(49.1)$ \\
\hline 16-24 year & $21,983(76.8)$ & $43,753(51.8)$ \\
\hline \multicolumn{3}{|l|}{ ICD-10 chapter } \\
\hline Infants (0 years) & $11,650(58.1)$ & $13,685(27.7)$ \\
\hline 1-4 year & $11,176(62.9)$ & $22,399(40.1)$ \\
\hline 5-15 year & $10,326(66.7)$ & $18,309(42.1)$ \\
\hline 16-24 year & $20,212(70.5)$ & $36,462(42.3)$ \\
\hline
\end{tabular}




\section{Appendix B - Methodology}

\section{Emergency admission definition}

An admission was defined by continuous periods in hospital that could consist of several finished consultant episodes (FCEs - a period of hospital stay under a single consultant). Admissions that occurred within one day of the date of discharge or included a hospital transfer were considered as a single admission. For infants, we only considered emergency admissions that were at least seven days after their postnatal discharge.

Admissions were classed as emergency admissions based on the 'method of admission' variable in HES, which classifies admissions as elective, emergency, maternity or birth admissions.

\section{Primary diagnosis group: six broad groupings}

We classified indications for emergency admission using two classification methods. First, we grouped indications in six broad groups for admission: infections, chronic conditions, injuries, perinatal conditions (for the $<5$ year group) or pregnancy-related (for girls aged $>10$ years), signs or symptoms, or other. These six groupings were based on existing, published code lists[1-4] for the first four groups. As codes from the ICD-10 chapter 'Symptoms, signs and abnormal clinical and laboratory findings' made up a significant proportion of residual diagnosis codes, we created a separate category for these codes. Remaining codes were grouped as 'other'.

The code list for chronic conditions defined a chronic condition as any health problem requiring follow-up by health services in more than $50 \%$ of cases, where follow-up could be repeated hospital admission, specialist follow-up through outpatient department visits, medication, or use of support services such as physiotherapy. Chronic conditions were grouped according to the likely clinical pathways or specialist input required to manage the conditions. The list of ICD-10 codes was developed in collaboration with and reviewed by a clinical panel.

As the codes lists used for our grouping were developed separately, there was some overlap between the six groups. For instance, ICD-10 code 024.0 for pre-existing insulin-dependent diabetes mellitus in pregnancy was included in both the chronic condition and pregnancyrelated code lists. We developed decision rules to determine how to group ICD-10 codes which were included in multiple categories.

We first categorised codes relating to pregnancy or perinatal conditions. If codes from this group were included in code list for injuries, infections or chronic conditions (e.g. O23 Infections of genitourinary tract in pregnancy), we reclassified the code as part of the new group.

Next, we extracted codes relating to injury admissions. Similar to the pregnancy and perinatal condition diagnosis codes, codes were reclassified as infection or chronic condition when codes were also included in those code lists (e.g. T43 - Poisoning by psychotropic drugs was reclassified as self-harm and included as a chronic condition). 
Codes that were grouped as both an infection and a chronic condition (e.g. B20 - Human immunodeficiency virus [HIV] disease resulting in infectious and parasitic diseases) were classified as chronic conditions.

Codes were categorised as 'Signs and symptoms' or 'Other' if they were not included in any of the four other code lists (e.g. R11 - Nausea and vomiting - was categorised as an infection code, as per Baker et al.[1]).

\section{Indications: ICD-10 chapter}

In addition, we grouped indications by ICD-10 chapter. We grouped chapters 19 and 20 ('Injury, poisoning and certain other consequences of external causes' and 'External causes of morbidity and mortality') together as both chapters refer to injuries. Due to small numbers we also grouped chapters 7 and 8 ('Diseases of the eye and adnexa' and 'Diseases of the ear and mastoid process') together.

For the interactive data visualisation, we included only the ten most common ICD-10 chapters for each group, and grouped the residual chapters in one 'other' group.

1 Baker MG, Barnard LT, Kvalsvig A, et al. Increasing incidence of serious infectious diseases and inequalities in New Zealand: a national epidemiological study. The Lancet 2012;379:1112-9. doi:10.1016/S0140-6736(11)61780-7

2 Hardelid P, Dattani N, Davey J, et al. Overview of child deaths in the four UK countries. HQIP bit.ly/hardelidreport

3 González-Izquierdo A, Cortina-Borja M, Woodman J, et al. Maltreatment or violencerelated injury in children and adolescents admitted to the NHS: comparison of trends in England and Scotland between 2005 and 2011. BMJ Open 2014.

4 Wijlaars L, Hardelid P, Woodman J, et al. Contribution of recurrent admissions in children and young people to emergency hospital admissions: retrospective cohort analysis of hospital episode statistics. Arch Dis Child 2014. 


\section{Appendix C - Static representation of interactive Figure 2}

For Figure 2, we have created an interactive data visualisation. As we could not submit this via the online submission system, we have created this appendix to give reviewers a flavour of what it looks like.

Figure 2 cross-tabulates the primary diagnosis group on index admission, and associated primary diagnoses upon readmission. Results are grouped by age group, and available for the six diagnosis groups (chronic conditions, infections, injury, perinatal/pregnancy-related, signs \& symptoms, and other) and by ICD-10 chapter (Figure C1).

By hovering over an index admission diagnosis category, e.g. infection, the Figure will display only those readmissions associated with that index admission diagnosis group (Figure C2). Counts and percentages are also updated to reflect the selection.

Readers can also opt to select a diagnosis group from the readmissions to see which primary diagnoses were recorded on index admission (Figure C3). 
Who comes back with what? Infants

Infants

Click here for: Grouping by ICD-10 chapter

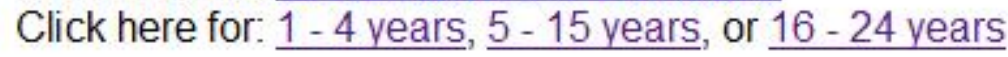

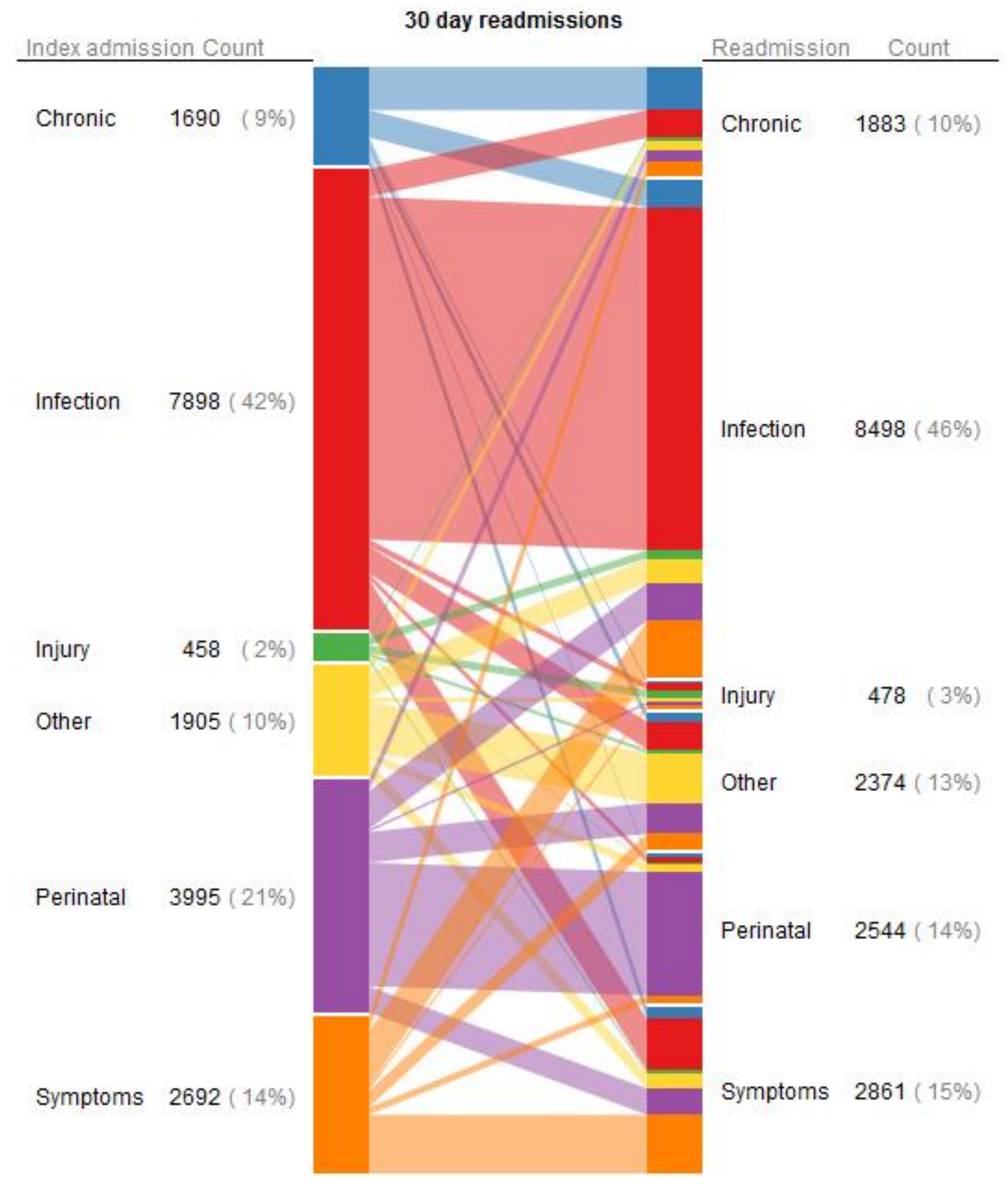

Figure $\mathrm{C} 1$ : Overview of primary diagnoses on index and readmission for infants, in six diagnosis groups 
Who comes back with what? Infants

Infants

Click here for: Grouping by ICD-10 chapter

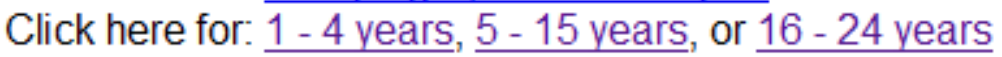

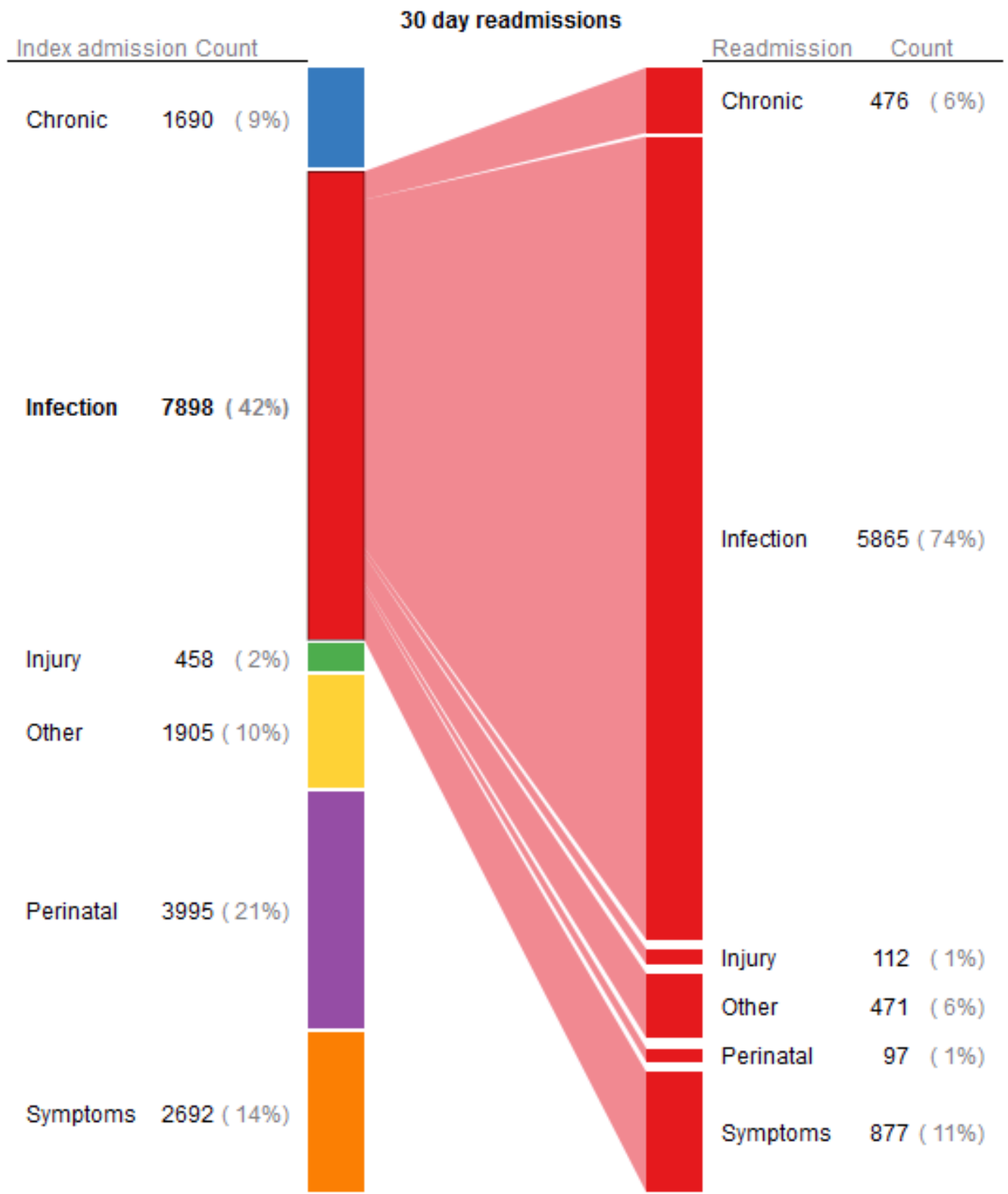

Figure C2: Overview of primary diagnoses on index and readmission for infants, in six diagnosis groups, selecting readmission diagnoses associated with an infection diagnosis on index admission 
Who comes back with what? Infants

Infants

Click here for: Grouping by ICD-10 chapter

Click here for: $\underline{1-4 \text { years, }} \underline{5-15 \text { years, or } 16-24 \text { years }}$

30 day readmissions

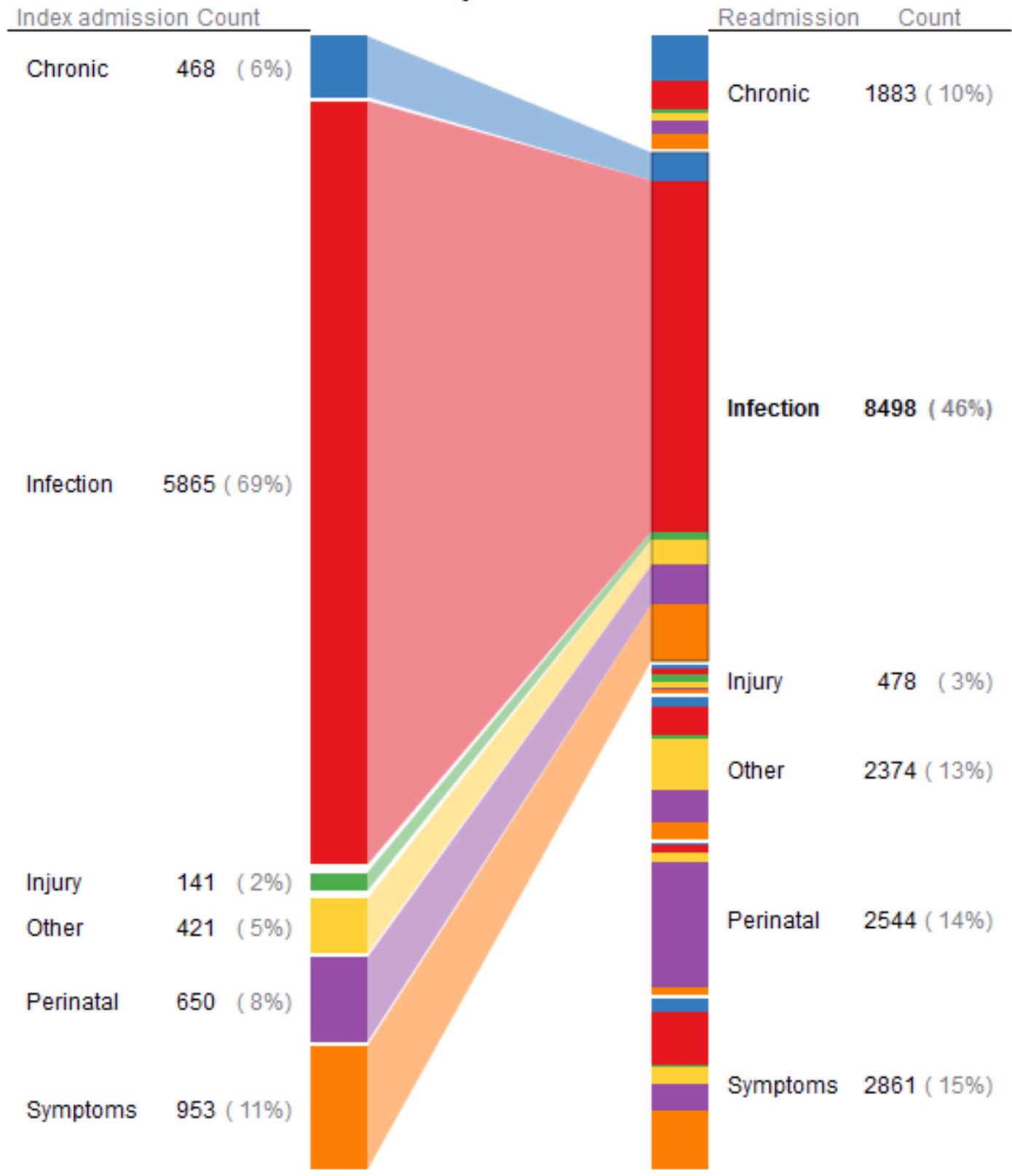

Figure C3: Overview of primary diagnoses on index and readmission for infants, in six diagnosis groups, selecting index admission diagnoses associated with an infection diagnosis on readmission 